\title{
Phloretin Attenuates Allergic Airway Inflammation and Oxidative Stress in Asthmatic Mice
}

\author{
Wen-Chung Huang ${ }^{1,2 \dagger}$, Li-Wen Fang ${ }^{3 \dagger}$ and Chian-Jiun Liou' ${ }^{2,4 *}$ \\ 'Graduate Institute of Health Industry Technology, Research Center for Industry of Human Ecology, Research Center for \\ Chinese Herbal Medicine, College of Human Ecology, Chang Gung University of Science and Technology, Taoyuan, Taiwan, \\ ${ }^{2}$ Division of Allergy, Asthma, and Rheumatology, Department of Pediatrics, Chang Gung Memorial Hospital, Taoyuan, \\ Taiwan, ${ }^{3}$ Department of Nutrition, I-Shou University, Kaohsiung, Taiwan, ${ }^{4}$ Department of Nursing, Research Center for \\ Chinese Herbal Medicine, Chang Gung University of Science and Technology, Taoyuan, Taiwan
}

\section{OPEN ACCESS}

Edited by: Kottarappat N. Dileepan, University of Kansas Medical Center,

Reviewed by:

David Dombrowicz, Institut national de la santé et de la recherche médicale, France Verica Paunovic,

University of Belgrade, Serbia

*Correspondence:

Chian-Jiun Liou

ccliu@mail.cgust.edu.tw

tThese authors have contributed equally to this work.

Specialty section: This article was submitted to Inflammation,

a section of the journal

Frontiers in Immunology

Received: 14 September 2016 Accepted: 26 January 2017 Published: 13 February 2017

Citation:

Huang $W-C$, Fang L-W and Liou C-J (2017) Phloretin Attenuates Allergic Airway Inflammation and Oxidative

Stress in Asthmatic Mice.

Front. Immunol. 8:134. doi: 10.3389/fimmu.2017.00134
Phloretin (PT), isolated from the apple tree, was previously demonstrated to have antioxidative and anti-inflammatory effects in macrophages and anti-adiposity effects in adipocytes. Inflammatory immune cells generate high levels of reactive oxygen species (ROS) for stimulated severe airway hyperresponsiveness (AHR) and airway inflammation. In this study, we investigated whether PT could reduce oxidative stress, airway inflammation, and eosinophil infiltration in asthmatic mice, and ameliorate oxidative and inflammatory responses in tracheal epithelial cells. BALB/c mice were sensitized with ovalbumin (OVA) to induce asthma symptoms. Mice were randomly assigned to the five experimental groups: normal controls; OVA-induced asthmatic mice; and OVA-induced mice injected intraperitoneally with one of the three PT doses $(5,10$, or $20 \mathrm{mg} / \mathrm{kg}$ ). In addition, we treated inflammatory human tracheal epithelial cells (BEAS-2B cells) with PT to assess oxidative responses and the levels of proinflammatory cytokines and chemokines. We found that PT significantly reduced goblet cell hyperplasia and eosinophil infiltration, which decreased AHR, inflammation, and oxidative responses in the lungs of OVA-sensitized mice. PT also decreased malondialdehyde levels in the lung and reduced Th2 cytokine production in bronchoalveolar lavage fluids. Furthermore, PT reduced ROS, proinflammatory cytokines, and eotaxin production in BEAS-2B cells. PT also suppressed monocyte cell adherence to inflammatory BEAS-2B cells. These findings suggested that PT alleviated pathological changes, inflammation, and oxidative stress by inhibiting Th2 cytokine production in asthmatic mice. PT showed therapeutic potential for ameliorating asthma symptoms in the future.

Keywords: asthma, cytokine, eosinophil, oxidative stress, phloretin

\section{INTRODUCTION}

Allergic asthma is a complex, chronic inflammatory airway disease. Patients with sudden, acute asthma attacks exhibit shortness of breath, dry coughing, chest tightness, paroxysmal wheezing due to airway obstruction, troubled breathing, and even death (1). In recent years, public health surveys found that the mortality due to acute asthma was increasing in developing countries (2). Asthma progression involves pathology in the respiratory system, characterized by airway smooth muscle 
proliferation, the airway narrowing, and goblet cell hyperplasia, accompanied by mucus hypersecretion, pulmonary eosinophilia, and airway hyperresponsiveness (AHR) $(3,4)$.

Recent studies have shown that the bronchial asthma is an inappropriate anaphylactic immune response to chronic lung inflammatory disease. Several immune cells, including Th2 cells, mast cells, eosinophils, and airway epithelial cells, secrete cytokines, chemokines, and inflammatory mediators that damage lung tissue and lead to the restricted breathing (4). Importantly, activated Th2 cells release additional cytokines, including IL-4, IL-5, and IL-13, to stimulate IgE production, which then causes mast cell activation, goblet cell hyperplasia, with excessive mucus secretion, eosinophil infiltration, and AHR (5). Furthermore, inflammatory immune cells, including eosinophils, neutrophils, monocytes, and epithelial cells, generate high levels of reactive oxygen species (ROS) to damage lung tissue $(6,7)$. Hence, asthma progression may be ameliorated by regulating the activity of Th2 cells and reducing the infiltration of inflammatory immune cells.

Phloretin (PT), a flavonoid of the chalcone class, is found in the fruit, leaves, and bark of apple trees (8). PT has many biological functions; it was shown to regulate glucose transporters, promote apoptosis in tumor cells, and enhance lipid metabolism to defend against obesity $(9,10)$. PT was also found to have antioxidase activity, which reduced oxidative damage in a rat model of cerebral ischemia (11).

Our earlier studies demonstrated that PT reduced the inflammatory and oxidative stress in LPS-induced acute lung injury mice (12). PT also suppressed inflammatory mediator expression in IL-1 $\beta$-stimulated lung epithelial cells (10). Therefore, we reasoned that PT might improve asthma by blocking inflammatory responses and oxidative stress. In the current study, we treated asthmatic mice with intraperitoneal injections of PT to investigate whether PT could ameliorate the pathogenesis of asthma. We evaluated inflammation, oxidative stress, and immune function in asthmatic mice.

\section{ANIMALS AND METHODS}

\section{Animals}

Female BALB/c mice (6-8 weeks old) were obtained from the National Laboratory Animal Center in Taiwan. All mice were housed in air-conventional animal housing with food and water ad libitum. Animal care and experimental procedures were performed in accordance with the guidelines of the Laboratory Animal Care Committee of Chang Gung University of Science and Technology (IACUC approval number: 2014-023).

\section{Sensitization, Airway Challenge, and Drug Treatment}

Phloretin (extracted from apple wood; $\geq 99 \%$ purity by HPLC; purchased from Sigma-Aldrich, St. Louis, MO, USA) was dissolved in DMSO. Mice were sensitized with intraperitoneal injections $(200 \mu \mathrm{l})$ that contained $50 \mu \mathrm{g}$ ovalbumin (OVA; Sigma, St. Louis, MO, USA) mixed with $2 \mathrm{mg}$ aluminum hydroxide (Thermo, Rockford, IL, USA) in normal saline. Injections were performed on days 1-3 and 14, as described previously (13). On days $14,17,20,23$, and 27 , mice were challenged with inhalations of $2 \%$ OVA for $30 \mathrm{~min}$, delivered with an ultrasonic nebulizer (DeVilbiss Pulmo-Aide 5650D, USA). One hour before the OVA inhalation challenge, mice were treated with or without intraperitoneal injections of PT. Then, the OVA challenge was followed by an AHR assay. Mice were randomly divided into five groups (12 mice each), as follows: healthy mice sensitized with normal saline and were given equal volume of DMSO by intraperitoneal injection (N group) (2); mice sensitized with OVA and were given equal volume of DMSO by intraperitoneal injection (OVA group); OVA-sensitized mice treated with 5, 10, or $20 \mathrm{mg} / \mathrm{kg}$ PT (PT5, PT10, and PT20 groups, respectively).

\section{Measurement of AHR}

Airway hyperresponsiveness was measured to assess airway function after inhaling aerosolized methacholine, as described previously (14). All mice inhaled $0-40 \mathrm{mg} / \mathrm{ml}$ methacholine for $3 \mathrm{~min}$; then, mice were placed in a single-chamber, whole-body plethysmograph (Buxco Electronics, Troy, NY, USA) to record the enhanced pause (Penh), a variable for estimating the AHR.

\section{Splenocyte Cultures and Serum Collection}

Splenocytes $\left(5 \times 10^{6}\right.$ cells $\left./ \mathrm{ml}\right)$ were isolated and cultured in RPMI 1640 medium containing 10\% FBS (Biological Industries, Haemek, Israel), $100 \mathrm{U} / \mathrm{ml}$ penicillin and streptomycin, and $100 \mu \mathrm{g} / \mathrm{ml}$ OVA for five continuous days. The supernatants were collected, and cytokine concentrations were measured, as previously described (13).

Blood collected from the orbital vascular plexus and centrifuged at $6,000 \mathrm{rpm}$ for $5 \mathrm{~min}$. The serum collected and stored at $-80^{\circ} \mathrm{C}$ as previously described. Serum was measure OVAspecific antibodies with an enzyme-linked immunosorbent assay (ELISA).

\section{Histological Analysis of Lung Tissue}

Lung tissues were fixed in $10 \%$ formalin, embedded in paraffin, and cut into sections $6 \mu \mathrm{m}$ thick. Sections were stained with hematoxylin and eosin (HE), to examine eosinophil infiltration Inflammatory index calculated and evaluated score using fivepoint scoring system as described previously (15). The score were considered by the inflammatory cell infiltration on perivascular regions and peribronchial of lungs. Furthermore, tracheal sections were stained with the periodic acid-Schiff (PAS) staining system (Sigma), to measure goblet cell hyperplasia, as described previously (14).

\section{Malondialdehyde (MDA) Activity}

We measured MDA activity in lung tissues with the lipid peroxidation assay kit, according to the manufacturer's instructions (Sigma). MDA activity was measured as nanomolars of MDA in milligram weight of wet tissue with a Multi-Mode Microplate Reader (BioTek SynergyHT, Bedfordshire, UK).

\section{Glutathione (GSH) Assay}

To detect glutathione levels in lung tissues, we employed a glutathione assay kit, according to the manufacturer's instructions 
(Sigma). The kit measured total glutathione, glutathione disulfide, and reduced glutathione. The glutathione reaction was measured spectrophotometrically at $412 \mathrm{~nm}$ with a microplate reader (Multiskan FC, Thermo, Waltham, MA, USA). Glutathione expressed as nanomolars of MDA in milligram weight of wet tissue.

\section{Bronchoalveolar Lavage Fluid (BALF) and Cell Counting}

Mice were anesthetized and sacrificed to collect BALF, as described previously (16). Mouse tracheas were intubated with an indwelling needle to wash the lungs with normal saline. The supernatants would assay cytokine and chemokine levels. We used Liu stain solution (Polysciences, Inc., Taipei, Taiwan) to differentiate cell morphology and determine cells counts.

\section{Enzyme-Linked Immunosorbent Assay}

Serum OVA-specific antibodies, including IgE and IgG1, were measured with a specific ELISA kit (BD Biosciences). Serum of OVA-sensitized mice makes OVA-IgG1 standard curves for determining the concentrations of IgG1. Serum was diluted fivefold to detect the absorbance of OVA-IgE at an optical density of $450 \mathrm{~nm}$, as previously described (14). Furthermore, the cell culture supernatants and BALF were used to measure with specific ELISA kits to detect the concentrations of CCL5, CCL11, CCL24, CCL26, intercellular adhesion molecule 1 (ICAM-1), IL-4, IL-5, IL-6, IL-8, IL-13, MCP-1, and tumor necrosis factor- $\alpha$ (TNF- $\alpha$ ), according to the manufacturer's instructions (R\&D Systems, Minneapolis, MN, USA), as previously described (16).

\section{RNA Isolation and Real-time PCR}

Lung tissues were homogenized, and RNA was extracted with TRIzol reagent (Life Technologies, Carlsbad, CA, USA); complementary DNA (cDNA) was generated from $1 \mu \mathrm{g}$ total RNA using cDNA synthesis kit (Life Technologies). cDNA gene expression assayed by real-time PCR performed with the SYBR Green system (Fermentas, Thermo, Waltham, MA, USA) and specific primers (Table 1) for the genes by the spectrofluorometric thermal cycler (iCycler; Bio-Rad Laboratories, Hercules, CA, USA). The average of gene cycle threshold $\left(C_{\mathrm{t}}\right)$ was measured for each experiment.
Relative cDNA expressions $\left(2^{-\Delta \Delta C_{t}}\right)$ for the specific genes were determined by the compared $C_{\mathrm{t}}$ method, which generates $\Delta \Delta C_{\mathrm{t}}$ as the discrepancy between the housekeeping genes $\beta$-actin and the specific gene for each sample.

\section{BEAS-2B Cell Culture and PT Treatment}

Phloretin was dissolved in DMSO at a concentration of $100 \mathrm{mM}$ to produce a stock solution. After dilution, the DMSO component was $\leq 0.1 \%$ of the experimental culture medium. We seeded immortalized human bronchial epithelial cells (BEAS-2B) into 24-well plates with DMEM/F12 medium. Cell cultures were pretreated with PT $(3-30 \mu \mathrm{M})$ for $1 \mathrm{~h}$, then treated with $10 \mathrm{ng} / \mathrm{ml}$ TNF- $\alpha$ for $24 \mathrm{~h}$, or $10 \mathrm{ng} / \mathrm{ml} \mathrm{TNF}-\alpha$ and $20 \mathrm{ng} / \mathrm{ml} \mathrm{IL-} 4$ for $24 \mathrm{~h}$. The supernatants were collected, and the levels of cytokines or chemokines were determined with specific ELISA kits.

\section{Cell-Cell Adhesion Assay}

BEAS-2B cells were treated with PT and stimulated with TNF- $\alpha$ for $24 \mathrm{~h}$. The human monocytic cell line, THP-1, was cultured and stained with calcein-AM solution (Sigma) for $0.5 \mathrm{~h}$, then cocultured with BEAS-2B cells for $1 \mathrm{~h}$. Adherent cells were observed and evaluated with fluorescence microscopy (Olympus, Tokyo, Japan).

\section{Determination of ROS Production}

TNF- $\alpha$-stimulated BEAS-2B cells treated with PT were seeded in 96-well plates for $24 \mathrm{~h}$. Next, cells were stained with $20 \mu \mathrm{M}$ $2^{\prime}, 7^{\prime}$-dichlorofluorescin diacetate (DCFH-DA) for $30 \mathrm{~min}$. Then, cells were lysed and analyzed with a Multi-Mode Microplate Reader (BioTek synergy HT); fluorescence was evaluated by exciting at $485 \mathrm{~nm}$ and measuring emission at $528 \mathrm{~nm}$. Furthermore, intracellular ROS was visualized with a fluorescence microscope (Olympus).

\section{Western Immunoblot Analysis}

Lung tissue proteins were quantified and separated on 10\% SDS polyacrylamide gels. The proteins were transferred to polyvinylidene fluoride (PVDF) membranes (Millipore, Billerica, MA, USA) and incubated with primary antibodies overnight at $4^{\circ} \mathrm{C}$. Then, membranes were washed and incubated with secondary

TABLE 1 | Primers used in real-time PCR analyses of cytokine and chemokine mRNA expression levels.

\begin{tabular}{|c|c|c|}
\hline Gene & Primer forward & Primer reverse \\
\hline CCL24 & AGGCAGTGAGAACCAAGT & GCGTCAATACCTATGTCCAA \\
\hline Gob5 & AATGGATGAATGGCTCAGTGAT & TATTGTAGGAGGATGCGTTGTC \\
\hline Intercellular adhesion molecule 1 & AACAGAATGGTAGACAGCAT & TCCACCGAGTCCTCTTAG \\
\hline $\mathrm{IFN}-\gamma$ & CAGCAACAACATAAGCGTCATT & АCСTCAAACTTGGCAATACTCA \\
\hline $\mid \mathrm{L}-13$ & GCTCCAGCATTGAAGCAGTG & CGTGGCAGACAGGAGTGTT \\
\hline iNOS & TTCCACAACCACСТCAAGCA & TTAAGGCATCACAGTCCGAGTC \\
\hline MUC5AC & AATGCTGGTGCCTGTGTCT & СCTCCTATGCCATCTGTTGTG \\
\hline$\beta$-Actin & AAGACCTCTATGCCAACACAGT & AGCCAGAGCAGTAATCTCCTTC \\
\hline
\end{tabular}


antibodies. Finally, PVDF membranes were treated with Luminol/ Enhancer Solution (Millipore) to detect antibody signals with the BioSpectrum 600 system (UVP, Upland, CA, USA). Primary antibodies included anti-HO-1, anti-Nrf2, and anti-Lamin B1 (Santa Cruz, CA, USA); $\beta$-actin expression was evaluated as a loading control (Sigma).

\section{Statistical Analysis}

Data were assessed with one-way analysis of variance, followed by the Tukey-Kramer post hoc test for multiple comparisons. All values represent the mean \pm SEM. Values of $p<0.05$ were considered significant.

\section{RESULTS}

\section{Effect of PT on Allergen-Induced AHR in Mice}

We evaluated whether PT could improve shortness of breath and abnormal airflow in the airways of asthmatic mice. Airway function was evaluated as the AHR, and the Penh value was calculated to determine the AHR. Mice were placed into the single-chamber whole-body plethysmograph to record the Penh, during inhalation of various methacholine doses $(0-40 \mathrm{mg} / \mathrm{ml})$. We found that, upon inhaling methacholine, the Penh value increased in a dose-dependent manner. The Penh values were greater in OVA-sensitized mice compared to normal mice (Figure 1A). At $40 \mathrm{mg} / \mathrm{ml}$ of inhaled methacholine, PT-treated asthmatic mice showed significantly lower Penh values (PT5, $5.9 \pm 0.66$, $p=0.32$; PT10, $4.41 \pm 0.58, p<0.05$; PT20, $3.94 \pm 0.48, p<0.01)$ compared to asthmatic mice in the OVA-sensitized group (OVA, $6.96 \pm 0.78)$. Hence, PT could significantly diminish AHR in asthmatic mice.

\section{PT Effect on Inflammatory Cells in BALF}

We counted various types of inflammatory cells to assess whether PT decreased the inflammatory response in asthmatic mice by reducing the numbers of inflammatory cells in BALF (Figure 1B). Asthmatic mice treated with PT had significantly reduced numbers of eosinophils and total cells compared to the OVA group (eosinophils: PT5: $6.2 \times 10^{5} \pm 6.9 \times 10^{4}, p=0.57$;
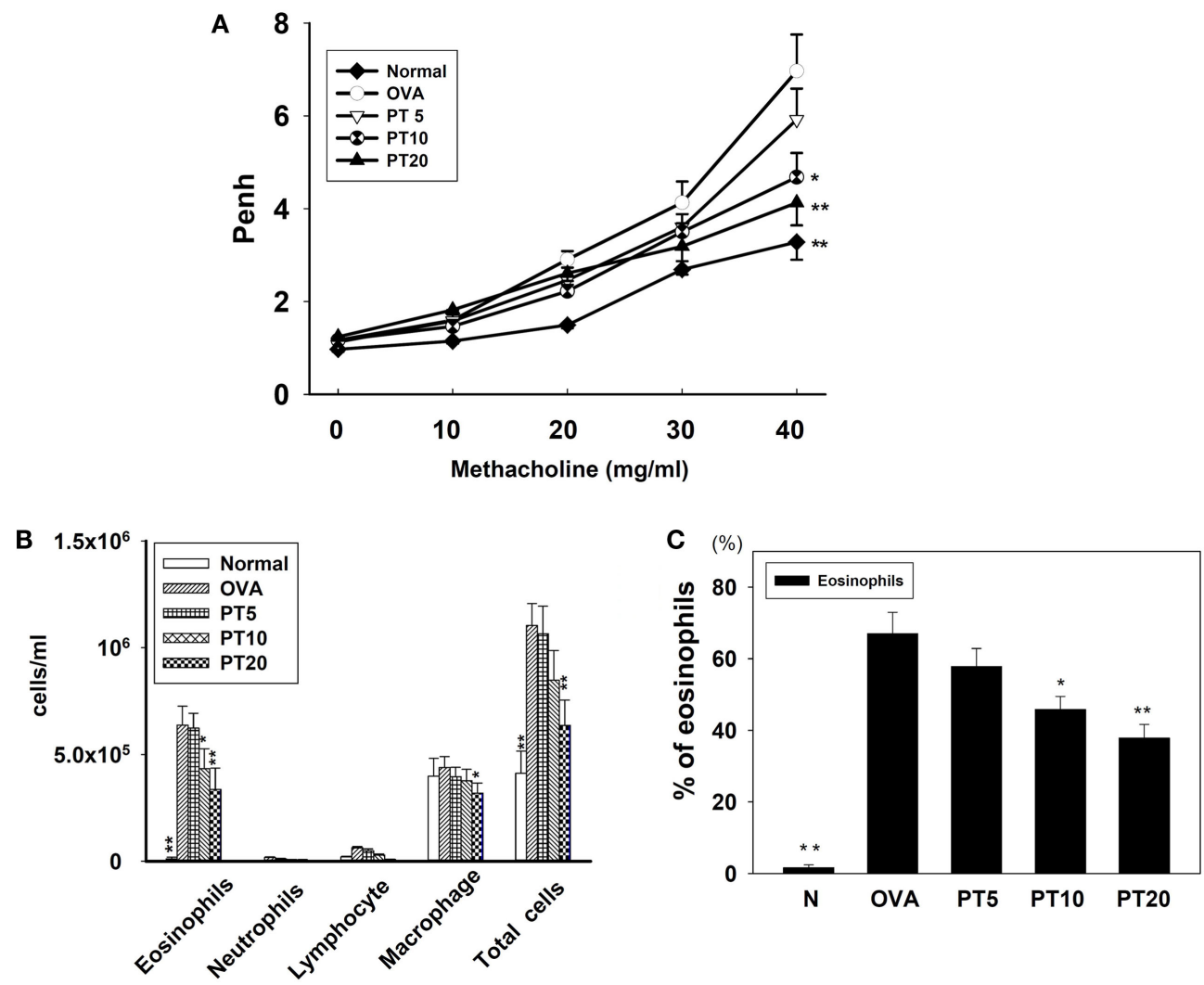

FIGURE 1 | The effect of phloretin (PT) on airway hyperresponsiveness (AHR) and cell counts in bronchoalveolar lavage fluid (BALF) of asthmatic mice. (A) Changes in AHR (Penh values) with inhalation of increasing methacholine doses (10-40 mg/ml) in normal (N) and OVA-stimulated (OVA) mice, without or with PT (PT5-20) treatment ( $n=12$ mice/group, measured in three independent experiments). (B) Numbers of inflammatory cells and total cells in BALF with increasing PT doses; (C) percentage of eosinophils in BALFs from OVA-sensitive mice, treated or untreated with PT. All data are presented as means \pm SEM. ${ }^{\star} p<0.05$ compared to OVA control group. ${ }^{* *} p<0.01$ compared to the OVA control group. Three independent experiments were analyzed and compared with the OVA-sensitive mice. 
PT10: $4.3 \times 10^{5} \pm 9.3 \times 10^{3}, p<0.05$; PT20: $3.3 \times 10^{5} \pm 1.1 \times 10^{4}$, $p<0.01$ vs. OVA: $6.4 \times 10^{5} \pm 8.9 \times 10^{4}$ ) (total cells: PT5: $1.0 \times 10^{6} \pm 1.3 \times 10^{5}, p=0.84 ;$ PT10: $8.4 \times 10^{5} \pm 1.3 \times 10^{4}, p=0.24$ PT20: $6.3 \times 10^{5} \pm 1.2 \times 10^{4}, p<0.01$ vs. OVA: $\left.1.1 \times 10^{6} \pm 1.0 \times 10^{5}\right)$. Furthermore, the proportion of eosinophils in BALF derived from the $\mathrm{P} 10$ or the $\mathrm{P} 20$ group was significantly reduced compared to the proportion in the OVA group (Figure 1C).

\section{PT Modulated Chemokine and Cytokine Levels in BALF and Lung Tissue}

The levels of cytokines and chemokines in BALF were determined by ELISA (Figure 2). Our results showed that PT could significantly suppress IL-4 levels compared to OVA-sensitization alone (PT5: $32.4 \pm 6.2 \mathrm{pg} / \mathrm{ml}, p=0.33$; PT10: $24.3 \pm 5.2 \mathrm{pg} / \mathrm{ml}, p<0.05$; PT20: $18.5 \pm 4.8$ pg/ml, $p<0.05$ vs. OVA: $41.3 \pm 3.8$ pg/ml). In addition, the PT groups had significantly decreased the levels of CCL11, CCL24, TNF- $\alpha$, IL-6, IL-5, and IL-13 compared to the OVA group. A real-time PCR analysis of the expression of genes in lung tissue showed that PT could significantly decrease the levels of CCL11, CCL24, and ICAM-1 expression compared to the levels in OVA-sensitized asthmatic mice. PT also inhibited IL-4, IL-5, IL-13, MUC5AC, Gob5, iNOS, and COX-2 gene expression.
Furthermore, PT increased the expression of IFN- $\gamma$ compared to the expression in asthmatic mice (Figure 3).

\section{Effect of PT on Eosinophil Infiltration and Goblet Cell Hyperplasia in Lungs}

Eosinophil infiltration in the lungs was evaluated with HE staining. Compared to normal mice, OVA-sensitized mice exhibited more infiltrating eosinophils between the bronchus and blood vessels (Figures 4A,B). PT reduced eosinophil infiltration in the lungs of asthmatic mice. We evaluated tracheal goblet cell hyperplasia with PAS staining. We found that PT could inhibit goblet cell hyperplasia compared to untreated, OVA-sensitized asthmatic mice (Figures 4C,D).

\section{Effects of PT on GSH and MDA Activity in the Lung}

Acute asthma attacks can also cause oxidative stress. Previous studies showed that the expression of antioxidant HO-1 could protect and decrease lung damage during oxidative stress (17). We found that the lungs in PT-treated mice had increased HO-1 expression of lung compared to asthmatic mice. Nrf2, is a transcription factor, could translocate into the nucleus to
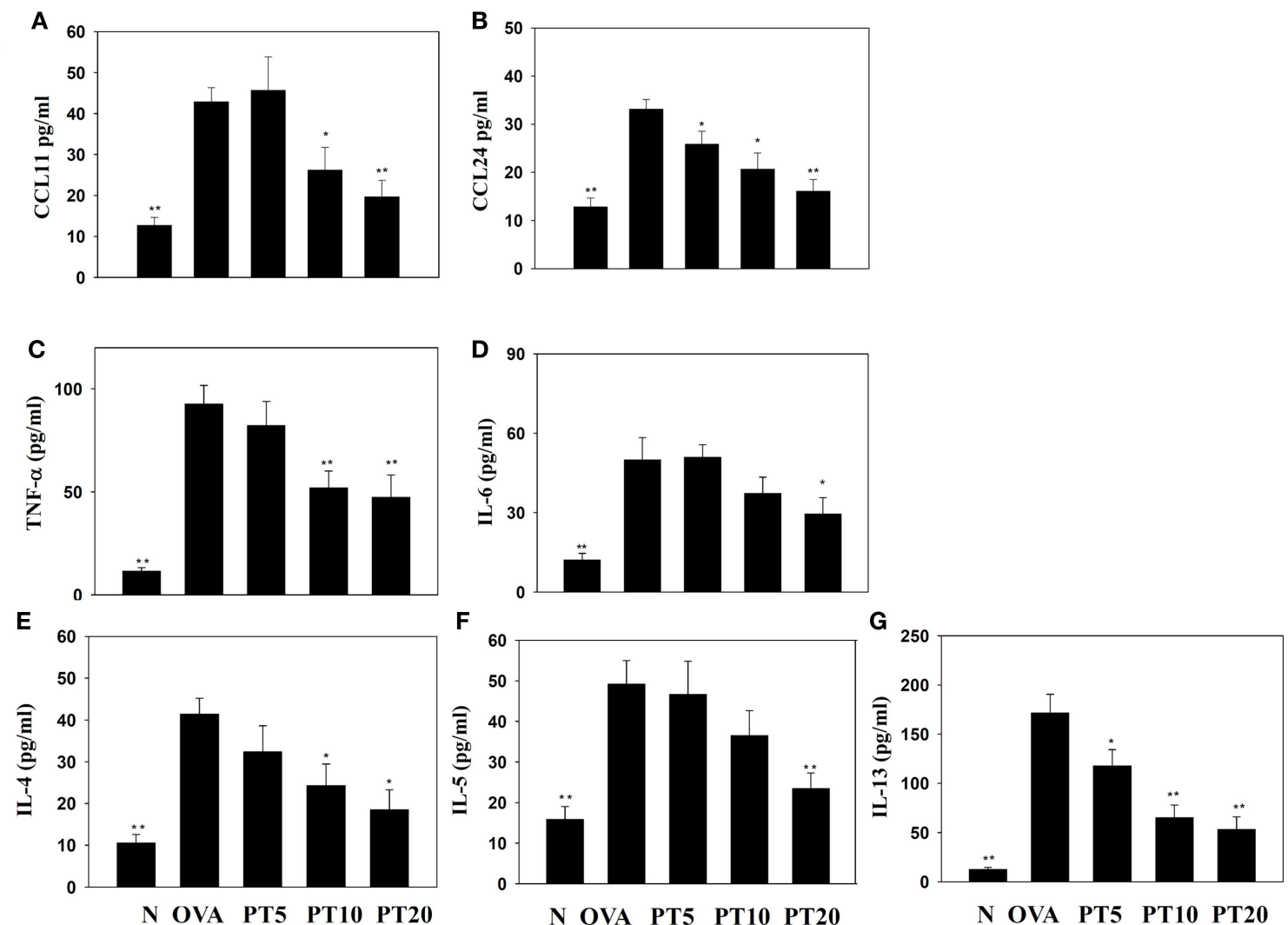

FIGURE 2 | Effects of phloretin (PT) on the levels of cytokines and chemokines in bronchoalveolar lavage fluid (BALF). The concentrations of (A) CCL11, (B) CCL24, (C) tumor necrosis factor- $\alpha$ (TNF- $\alpha$ ), (D) IL-6, (E) IL-4, (F) IL-5, and (G) IL-13 were measured by enzyme-linked immunosorbent assay in BALF from normal (N) and OVA-stimulated (OVA) mice, without or with PT (PT5-20) treatment. All data are presented as the means \pm SEM. ${ }^{*} p<0.05$ compared to the OVA control group. ${ }^{\star \star} p<0.01$ compared to the OVA control group. Three independent experiments were analyzed and compared with the OVA-sensitive mice. 

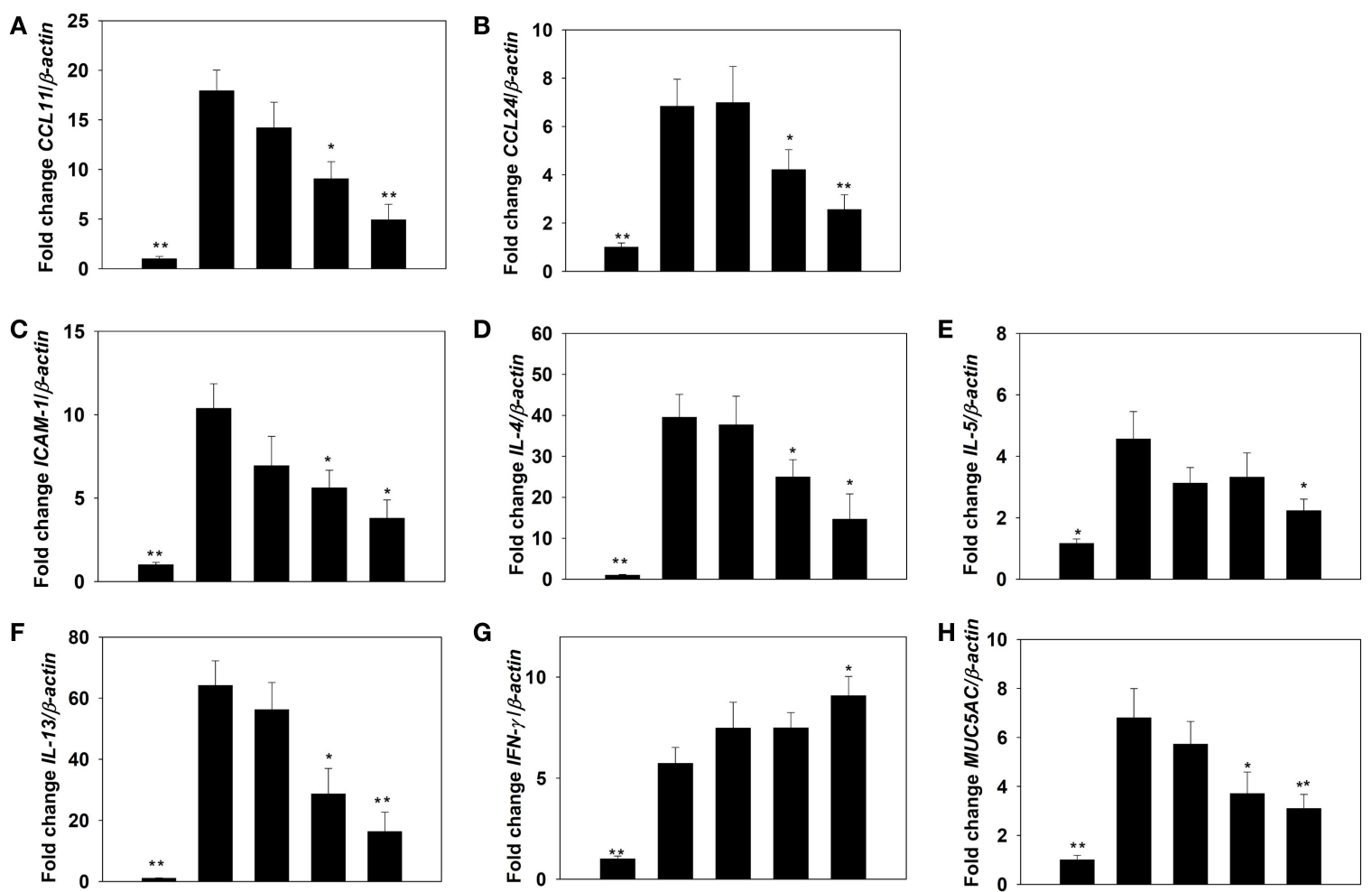

G
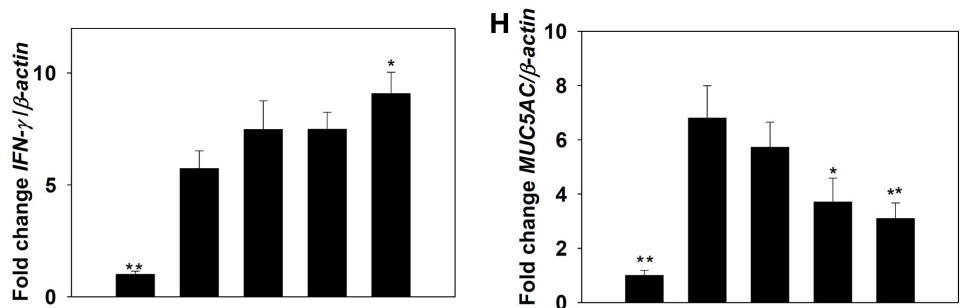

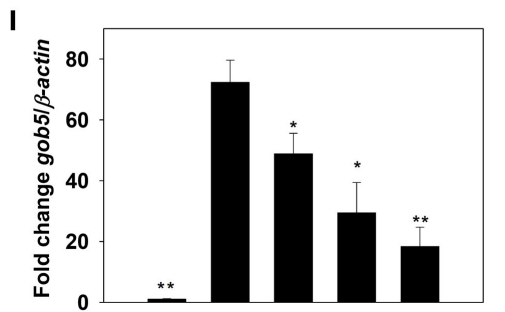

N OVA PT5 PT10 PT20

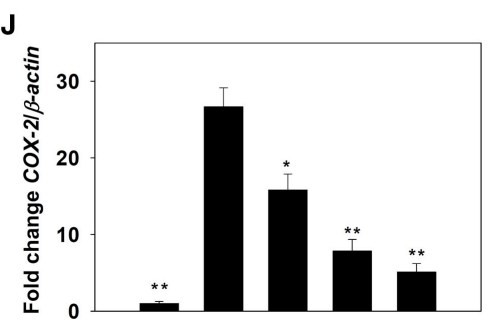

N OVA PT5 PT10 PT20

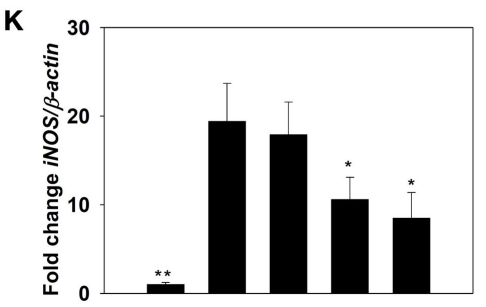

N OVA PT5 PT10 PT20

FIGURE 3 | Phloretin (PT) effects on cytokine, chemokine, and inflammatory mediator mRNA expression in the lungs. Gene expression levels of (A) CCL11, (B) CCL24, (C) ICAM-1, (D) IL-4, (E) IL-5, (F) IL-13, (G) IFN- $\gamma$, (H) MUC5AC, (I) Gob5, (J) COX-2, and (K) iNOS were determined by real-time RT-PCR of RNA extracted from lung tissues of normal (N) and OVA-stimulated (OVA) mice, without or with PT (PT5-20) treatment. Fold changes in expression were measured relative to the $\beta$-actin expression (internal control). Data are presented as the mean \pm SEM. ${ }^{*} p<0.05$ compared to OVA control mice. ${ }^{* \star} p<0.01$ compared to OVA control mice. Three independent experiments were analyzed and compared with the OVA-sensitive mice.

promote HO-1 expression for antioxidant response. PT could increase nuclear Nrf2 expression of lung cells compared to OVAsensitized asthmatic mice (Figure 5A). We also found that the OVA-sensitized asthmatic mice had significantly increased MDA activity and decreased GSH levels in lung tissues compared to the levels in normal mice (Figures 5B,C). However, PT significantly reduced MDA activity and promoted GSH production in lung tissues, compared to the levels in OVA-sensitized asthmatic mice.

\section{PT Modulated Splenocyte Cytokine Levels and Serum OVA-Specific Antibody}

Splenocyte culture supernatant analyses showed that PT significantly attenuated the levels of IL-4, IL-5, and IL-13, compared to untreated OVA-sensitized cells. PT also significantly decreased the levels of OVA-IgE and OVA-IgG1 in the serum of OVAsensitized asthmatic mice (Figure 6).

\section{PT Suppressed Inflammatory Mediators in Activated BEAS-2B Cells}

Phloretin could decrease IL-6, IL-8, CCL5, and MCP-1 levels in TNF- $\alpha$-activated BEAS-2B cells. When BEAS-2B cells were stimulated with TNF- $\alpha$ and IL-4, PT also significantly inhibited CCL11, CCL24, and CCL26 production (Figure 7).

\section{PT Reduced Monocytic Cell Adhesion to BEAS-2B Cells}

Phloretin significantly decreased ICAM- 1 expression in TNF- $\alpha$ activated BEAS-2B cells (Figure 8A). We also evaluated whether 
A
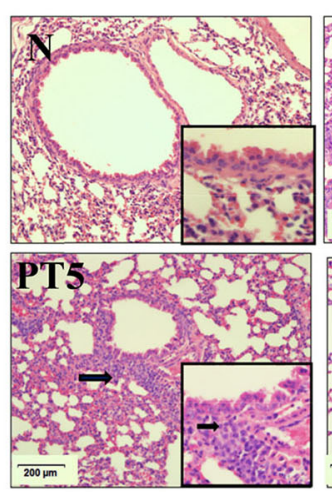

C
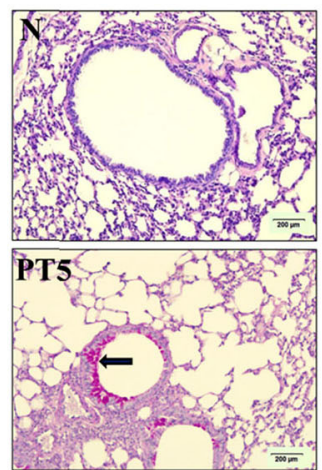
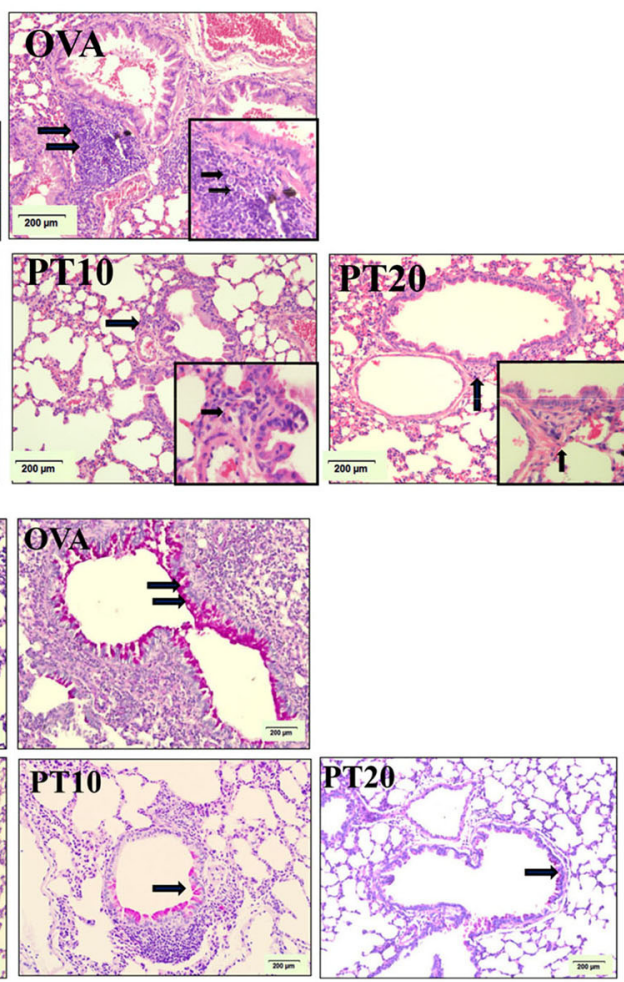

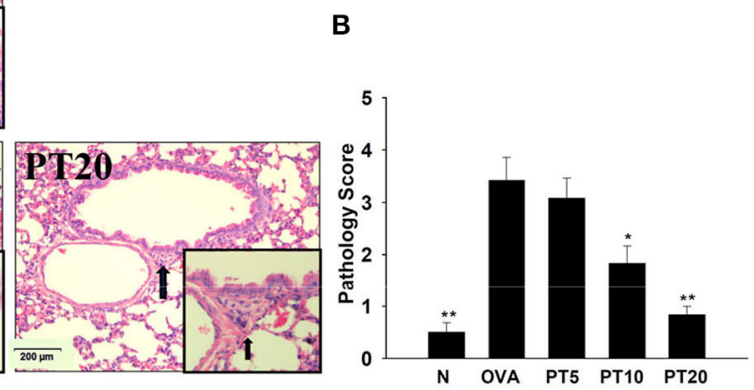

D

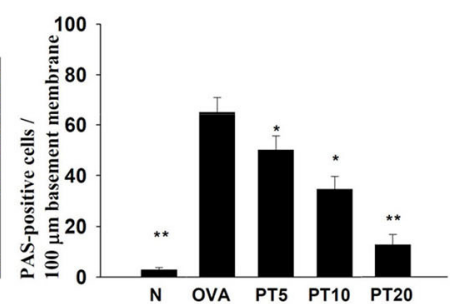

FIGURE 4 | Phloretin (PT) effects on asthmatic lung tissue. Histological sections of lung tissues from normal (N) and OVA-stimulated (OVA) mice, without or with PT (PT5-20) treatment. (A) PT reduced eosinophil infiltration; eosinophils are indicated with arrows (hematoxylin and eosin stain; 200x magnification). Amplification sections (400x magnification) were shown for the indicated areas. (B) Scoring of inflammation via pathological evaluation of inflammatory cell infiltration in lung sections. (C) Periodic acid-Schiff (PAS)-stained lung sections show goblet cell hyperplasia; goblet cells are indicated with arrows (200x magnification). (D) Results were expressed as the number of PAS-positive cells per $100 \mu \mathrm{m}$ of basement membrane. All data are presented as the means \pm SEM. ${ }^{*} p<0.05$ compared to the OVA control group. ${ }^{* *} p<0.01$ compared to the OVA control group. Three independent experiments were analyzed and compared with the OVA-sensitive mice.

PT could inhibit the attachment of THP-1 monocyte cells to inflammatory BEAS- $2 \mathrm{~B}$ cells. TNF- $\alpha$-stimulated BEAS-2B cells were cocultured with THP-1 cells (stained with calcein AM). PT treatment significantly reduced THP-1 cell adherence to TNF- $\alpha$ activated BEAS-2B cells (Figures 8B,C).

\section{Effect of PT on ROS Production}

BEAS-2B cells were stained with DCFH-DA, the cells were lysed, and ROS production was quantified with a Multi-Mode Microplate Reader. We found that PT reduced ROS production in TNF- $\alpha$-activated BEAS-2B cells (Figure 9A). Furthermore, we examined intracellular ROS in intact cells with a fluorescence microscope. We observed that PT attenuated intracellular ROS expression in TNF- $\alpha$-activated BEAS-2B cells (Figures 9B,C).

\section{DISCUSSION}

Phloretin is a bioactive flavonoid derived from the apple tree. It has anti-inflammatory effects in inflammatory macrophages and human lung epithelial cells (4). Previous studies have shown that PT could regulate glucose transporters and increase lipolysis in
3T3-L1 adipocytes $(10,18)$. Our previous study found that PT improved the inflammatory and oxidative stress in LPS-induced acute lung injury mice (12). In the present study, we evaluated the hypothesis that PT might ameliorate the pathological manifestations of asthma in an asthmatic mouse model. These results suggested that PT could ameliorate local asthma symptoms in the lung by attenuating Th2 cell activity in the immune system of this experimental asthmatic model. PT acted by blocking the inflammatory response and alleviating oxidative stress.

Oxidative stress plays an important role in the development of several chronic diseases, including cardiovascular disorders, cancer, diabetes, and asthma (19). Asthma is a disorder involving pulmonary inflammation and allergic reaction; thus, excessive oxidative stress would exacerbate airway inflammation and cause aggravated bronchospasms that could worsen lung tissue damage (20). In several animal studies, excess ROS was reported to increase inflammatory cell infiltration into the lungs, stimulate extracellular matrix protein production, and stimulate proinflammatory cytokine production in airway epithelial cells $(21,22)$. It was previously shown that natural antioxidants could improve the pathological manifestations of asthma by blocking oxidative 
A

\section{N OVA PT5 PT10 PT20}
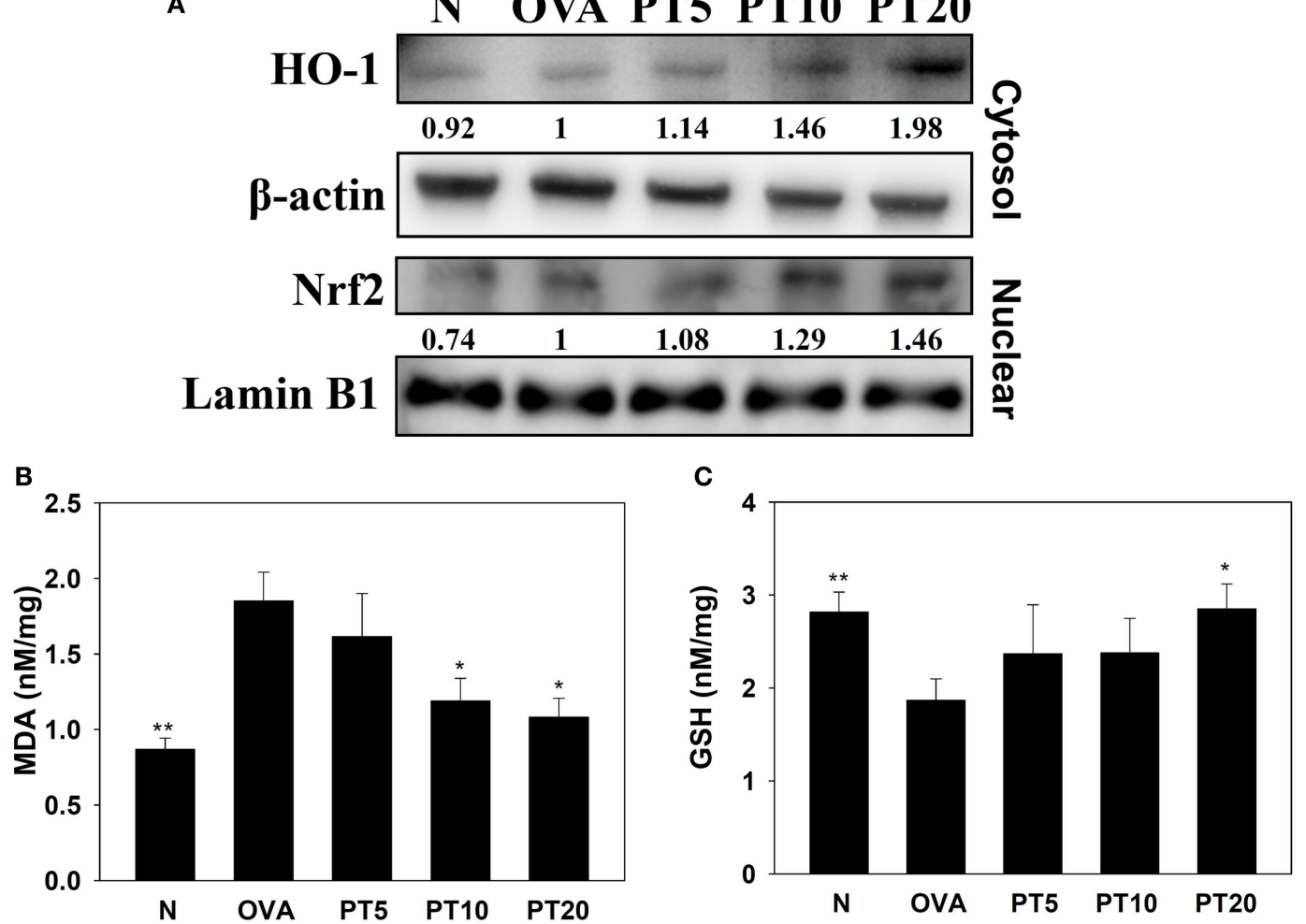

FIGURE 5 | Phloretin (PT) effects on oxidative stress factors. (A) Western blot shows PT modulation of HO-1 and Nrf2 expression in lung tissue of normal (N) and OVA-stimulated (OVA) mice, without or with PT (PT5-20) treatment. (B) Malondialdehyde (MDA) activity and (C) GSH activity in lung tissues of mice. Data are presented as the mean \pm SEM. ${ }^{*} p<0.05$ compared to OVA control mice. ${ }^{* *} p<0.01$ compared to OVA control mice. Three independent experiments were analyzed and compared with the OVA-sensitive mice.

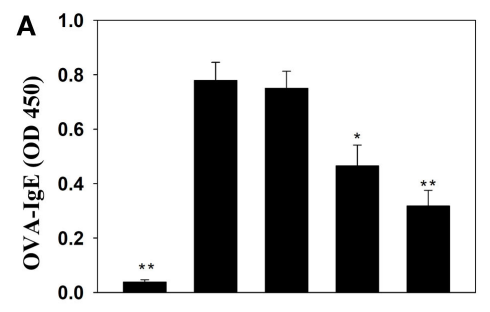

C

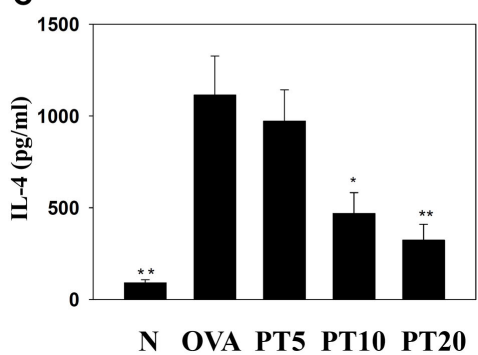

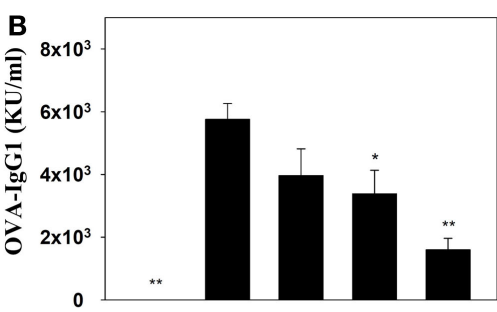

D

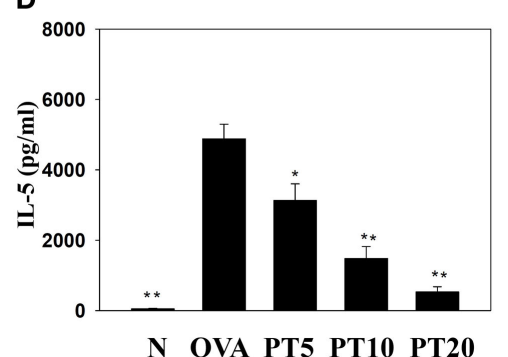

E

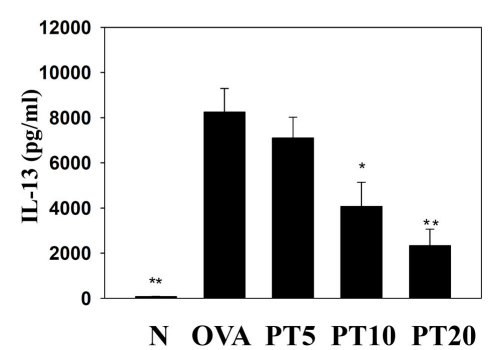

FIGURE 6 | Phloretin (PT) effects on OVA-specific antibodies in serum. Serum levels of (A) OVA-lgE and (B) OVA-lgG1 are shown from normal (N) and OVA-stimulated (OVA) mice, without or with PT (PT5-20) treatment. PT also changed the cytokine levels produced by OVA-activated splenocytes, including (C) IL-4, (D) IL-5, and (E) IL-13. All data are presented as the means \pm SEM. ${ }^{\star} p<0.05$ compared to the OVA control group. ${ }^{\star \star} p<0.01$ compared to the OVA control group. Three independent experiments were analyzed and compared with the OVA-sensitive mice. 

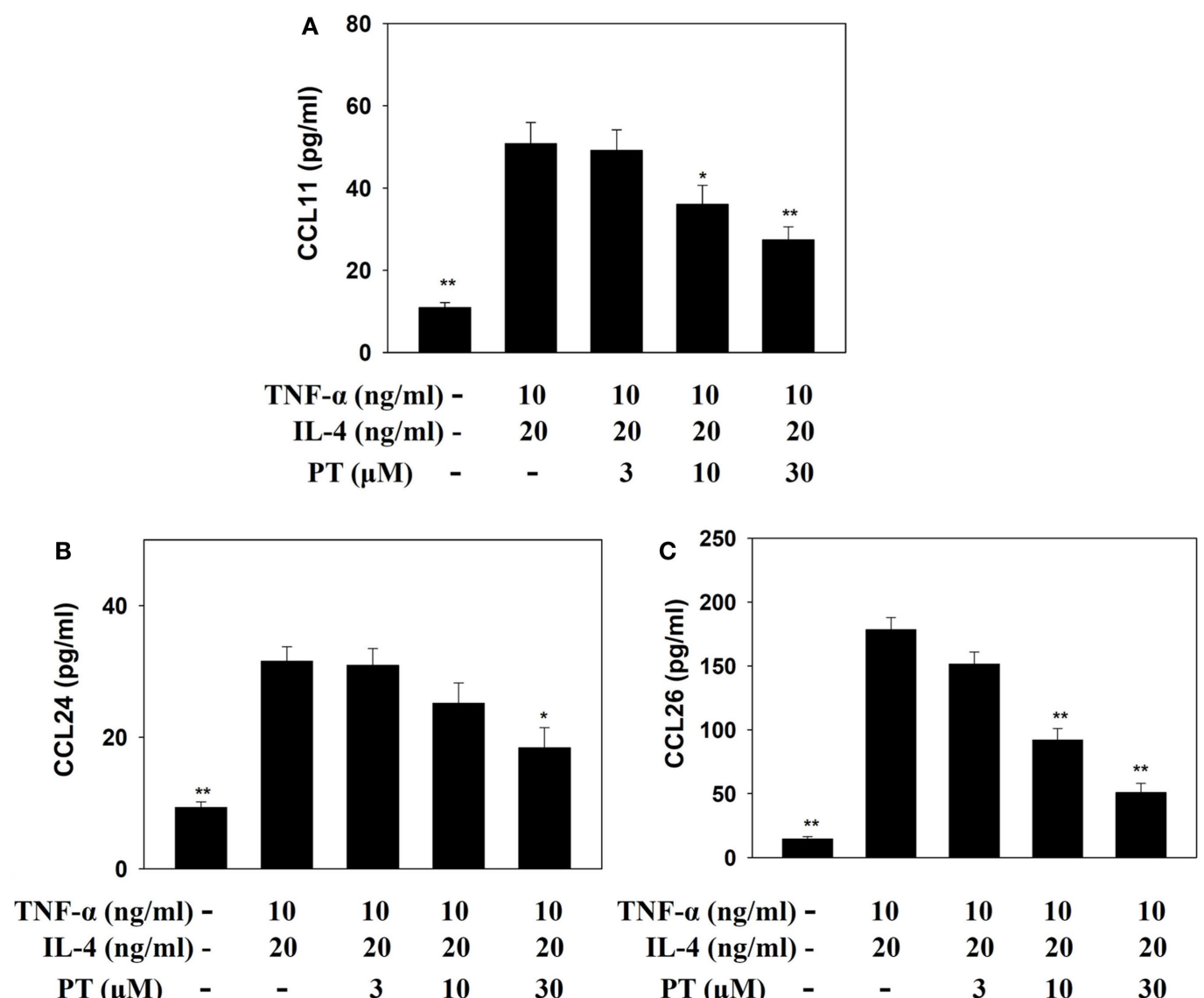

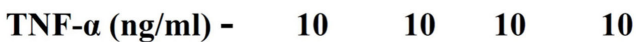
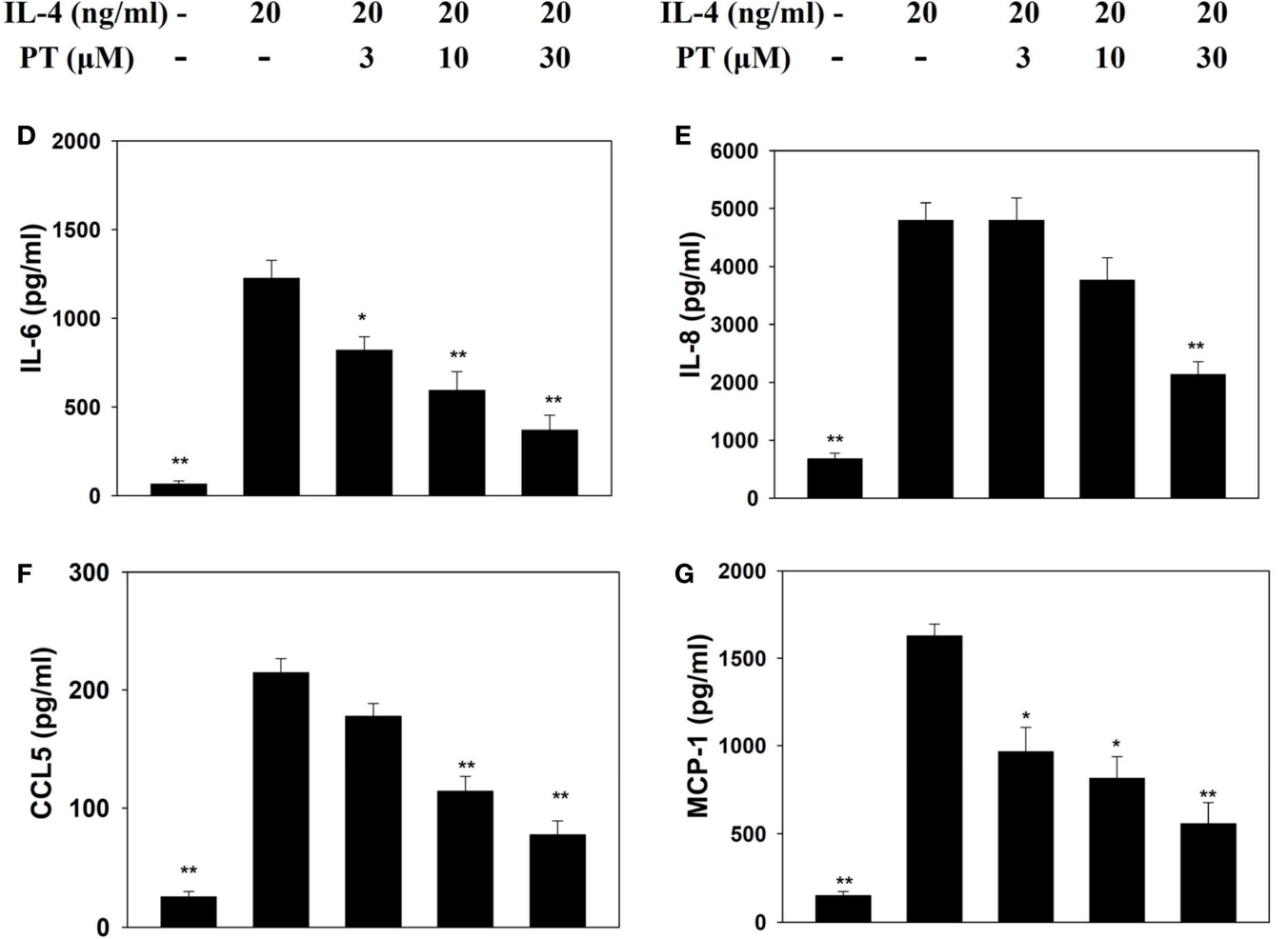

$\begin{array}{cccccc}\text { TNF- } \alpha(\mathrm{ng} / \mathrm{ml}) & - & 10 & 10 & 10 & 10 \\ \text { PT }(\mu \mathrm{M}) & - & - & 3 & 10 & 30\end{array}$

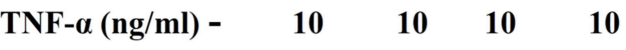

PT $(\mu \mathrm{M}) \quad-\quad-\quad 3010$

FIGURE 7 | Continued 


\section{FIGURE 7 | Continued}

Phloretin (PT) effects on cytokine and chemokine production in BEAS-2B cells. Enzyme-linked immunosorbent assay results show (A) CCL11, (B) CCL24, (C) CCL26, (D) IL-6, (E) IL-8, (F) CCL5, and (G) MCP-1 levels in BEAS-2B cells treated with tumor necrosis factor- $\alpha$ (TNF- $\alpha$ ), IL-4, and/or PT. The data represent the mean \pm SEM; ${ }^{\star} p<0.05$, ${ }^{\star *} p<0.01$, compared to BEAS-2B cells stimulated with TNF- $\alpha$ alone or TNF- $\alpha$ and IL-4. Three independent experiments were analyzed and compared with TNF- $\alpha$ alone or TNF- $\alpha$ and IL-4.

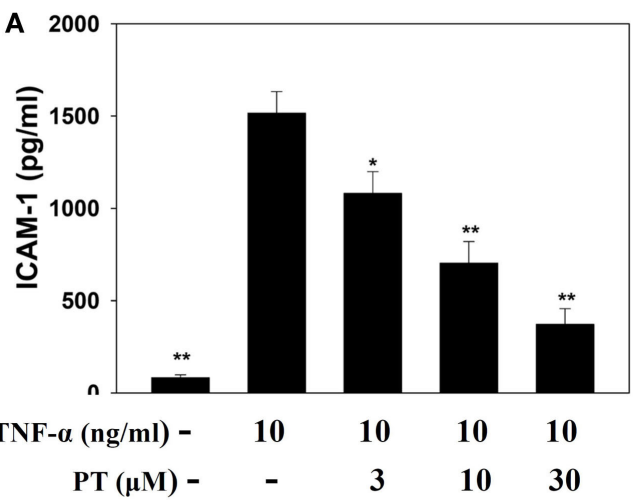

B
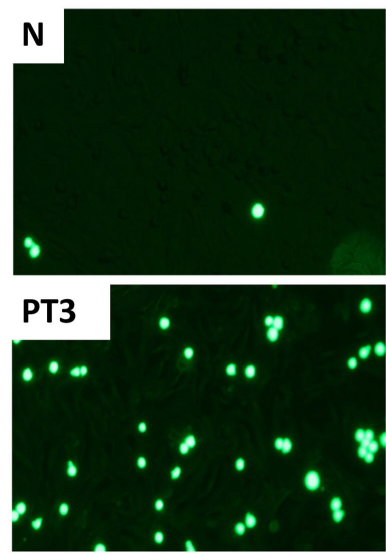
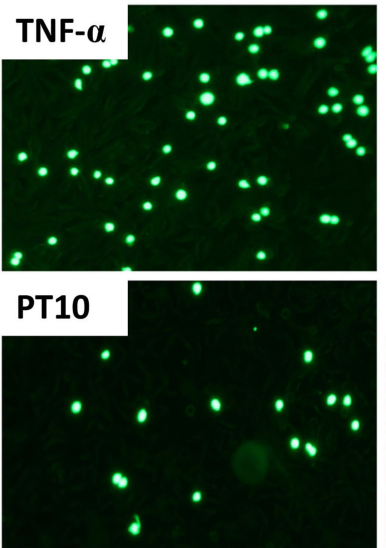

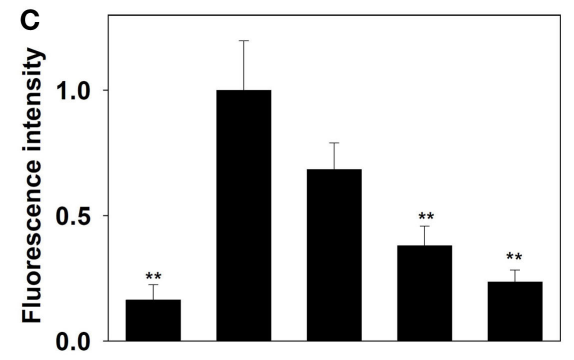

$\begin{array}{lllll}\text { TNF- } \alpha(\mathrm{ng} / \mathrm{ml})- & 10 & 10 & 10 & 10\end{array}$

FIGURE 8 | Phloretin (PT) inhibited THP-1 cell adherence to the activated BEAS-2B cells. (A) PT decreased the levels of intercellular adhesion molecule 1 (ICAM-1) in BEAS-2B cells activated with tumor necrosis factor- $\alpha$ (TNF- $\alpha)$. The data represent the mean \pm SEM; ${ }^{*} p<0.05$, ${ }^{* *} p<0.01$, compared to BEAS-2B cells stimulated with TNF- $\alpha$. (B) Fluorescence microscopy images of THP-1 cells labeled with calcein AM and mixed with normal (N) and TNF- $\alpha$-activated BEAS-2B cells, in the absence or presence of PT. (C) Fluorescence intensity of monocytic cell adhesion to BEAS-2B cells. The data represent the mean \pm SEM; ${ }^{\star} p<0.05$, ${ }^{* *} p<0.01$, compared to BEAS-2B cells stimulated with TNF- $\alpha$ alone or TNF- $\alpha$ and IL-4. Three independent experiments were analyzed and compared with TNF- $\alpha$ alone or TNF- $\alpha$ and IL-4.

stress in asthmatic mice $(4,23)$. Other studies showed that PT had antioxidative effects on inflammatory colorectal epithelial cells and attenuated oxidative reactions in rats that underwent cecal ligation and puncture-induced sepsis $(24,25)$. PT also improved oxidative injury in a rat model of cerebral ischemia (24).

Malondialdehyde is a lipid peroxidation marker. It is derived from prostaglandin biosynthesis in cells during oxidative stress (20). Antioxidant enzymes, such as GSH, catalase, and superoxide dismutase, offer protection from oxidation by suppressing the chronic inflammatory response and preventing the deterioration of lung tissue in allergic asthma $(20,22)$. In the current study, we demonstrated that PT significantly decreased MDA and increased GSH, which ameliorated oxidative stress in lung tissues of asthmatic mice. We also found that PT could increase nuclear Nrf2 expression, which contributed to increasing HO-1 expression, and provided protection from oxidation in asthmatic lungs. Furthermore, our findings demonstrated that PT could suppress ROS production in TNF- $\alpha$-activated human tracheal epithelial cells. Hence, we showed that PT could provide antioxidative effects to ameliorate lung injury in asthma.

Airway hyperresponsiveness is an important feature of asthma. Allergens might induce an acute asthma attack, which presents as bronchoconstriction and severe shortness of breath (1). Clinically, asthma is diagnosed in both children and adults by measuring the 

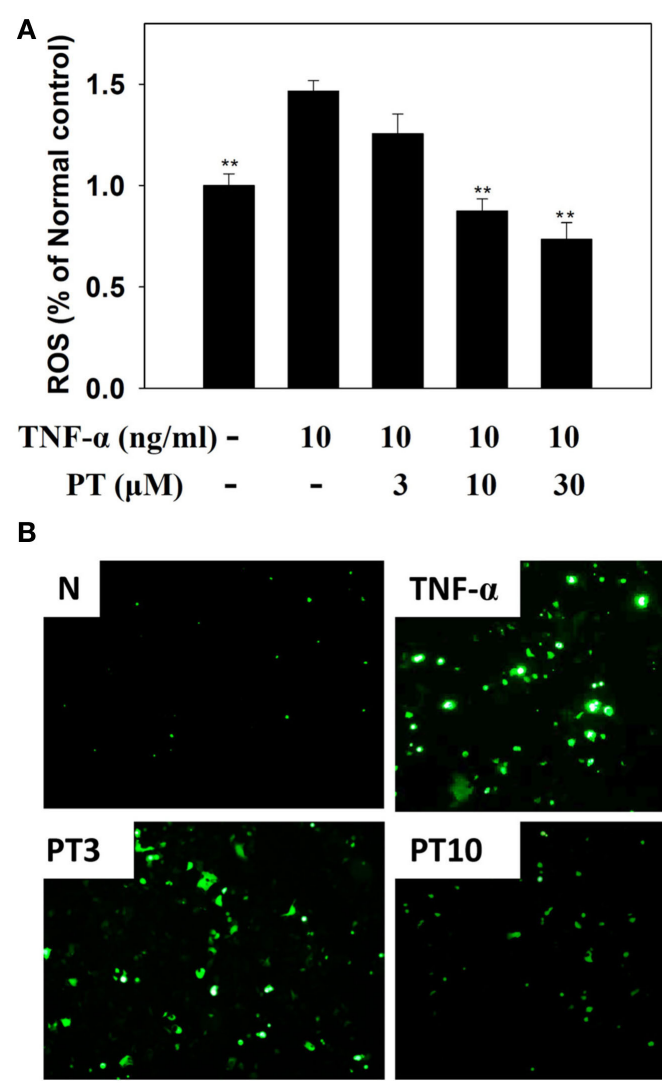
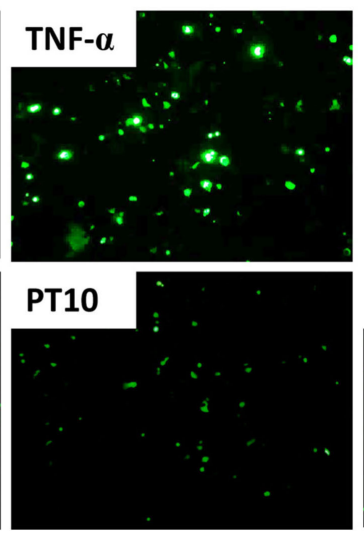
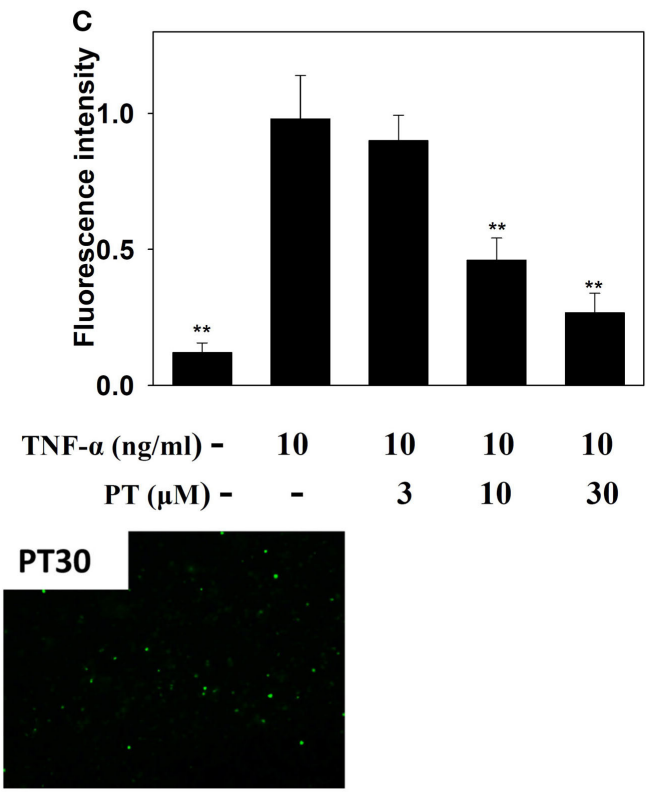

FIGURE 9 | Phloretin (PT) effects on reactive oxygen species (ROS) production in activated BEAS-2B cells. (A) Percentages of ROS detected in tumor necrosis factor- $\alpha(\mathrm{TNF}-\alpha)$-activated BEAS-2B cells in the absence or presence of PT, compared to untreated cells (N); (B) fluorescence microscopy images of intracellular ROS. (C) Fluorescence intensity of intracellular ROS. Data represent the mean \pm SEM; ${ }^{* *} p<0.01$, compared to BEAS-2B cells stimulated with TNF- $\alpha$ alone. Three independent experiments were analyzed and compared with TNF- $\alpha$ alone or TNF- $\alpha$ and IL-4.

AHR, evaluating the airflow, and investigating the pathological features of asthma $(22,26)$. In patients with asthma, oxidative stress enhances the production of proinflammatory mediators, increases the AHR, and stimulates mucin secretion in the airways (27). PT significantly reduced elevations in inflammatory mediators in BALF and lung tissue of OVA-induced asthmatic mice and decreased proinflammatory cytokines and chemokines in human tracheal epithelial cells; thus, PT could ameliorate lung damage in asthma. Previous studies suggested that IL-13, which is a Th2-associated cytokine, could aggravate AHR in patients with asthma (28). In patients with asthma, where airway function is deteriorated and inflammatory responses are induced, high IL-13 levels have been observed in BALF and lung (29). We found that PT treatment reduced the IL-13 levels in BALF and suppressed IL-13 gene expression in the lungs of asthmatic mice, which may have contributed to AHR attenuation.

Excessive secretion of Th2 cytokines exacerbates the severity of an allergic response by increasing inflammatory cell infiltration and inducing goblet cell hyperplasia, which in turn, causes excess mucus secretion in asthmatic lungs $(4,30)$. In patients with asthma, Th2 cells release elevated IL-5 levels, which increase eosinophil differentiation in bone marrow cells (6). Eotaxins
(CCL11 CCL24, and CCL26) are thought to attract eosinophil migration into inflamed lung tissues, and the release of more inflammatory mediators by activated eosinophils increases lung tissue injury $(5,29)$. Previous study demonstrated that eosinophil would secret major basic protein for induced mast cell degranulation to exacerbate allergy response (6). Eosinophil also released eosinophil cationic protein and eosinophil peroxidase to create the transmembrane channels for cytotoxic molecules into the cell (29). Hence, eosinophils accumulation in lung tissue would cause serious asthmatic allergy and inflammatory response. Eosinophils also induced the development of airway remodeling (5). Our results demonstrated that PT could inhibit IL-5, CCL11, and CCL24 expression in the lungs and BALF of asthmatic mice. PT also decreased the levels of CCL11, CCL24, and CCL26 in inflamed tracheal epithelial cells. Additionally, PT also reduced ICAM-1 in inflamed tracheal epithelial cells, which reduced their ability to adhere to inflammatory cells in lung tissues. Thus, PT could reduce eosinophil infiltration into lung tissue by blocking IL-5 and eotaxin production. Furthermore, activated macrophage also released more inflammatory cytokines to destroy the function of lung cell (31). In our murine asthma model, we found that asthma mice did not significantly increase 
macrophage infiltration in BALF compared to normal mice. Asthmatic mice only treated with $20 \mathrm{mg} / \mathrm{kg}$ PT had significantly reduced numbers of macrophage compared to the OVA group. However, eosinophil activation and proliferation would induce the development of asthma disease (4). Hence, macrophages did not significantly affect asthma symptoms in PT-treated asthmatic mice.

Moreover, IL-4 can activate B cells to secrete IgE and bind to mast cells; this binding activates the complex of allergic responsive $\mathrm{IgE}$ and mast cells, and they release leukotrienes and histamine; these factors cause acute allergic and inflammatory reactions in patients with asthma (28). Importantly, PT can decrease Th2 cell production of IL-4 to reduce the pathological characteristics of asthma.

In patients with asthma, allergens stimulate airways and induce smooth muscle cell proliferation, which causes airway narrowing and tracheal goblet cell proliferation, which aggravates mucus secretion (32). These effects cause shortness of breath and difficulty in breathing. Furthermore, IL-4 and IL-13 can activate and stimulate goblet cell hyperplasia in the trachea (29). Our observations in asthmatic mice showed that PT reduced goblet cell hyperplasia and suppressed excessive mucus secretion, which improved mucus congestion and airway asphyxia by blocking the expression of IL-4 and IL-13 in BALF and lung tissue.

Glucose transporter 2 (GLUT2) plays an important role for sensing the levels intestinal glucose (33). In adipocyte and hepatocyte, more glucose accumulate could convert to lipid. Obesity could increase the developing asthma in obese adults and children (34). PT (an inhibitor of GLUT2 transporter) could decrease glucose into intestinal serosal fluid (35). However, we did not evidence whether PT modulated glucose levels to improve asthma symptom in this experimental asthma model.
Collectively, we demonstrated that PT significantly reduced eosinophil infiltration and mucus hypersecretion by suppressing eotaxin and Th2 cytokine production in asthmatic mice. These results suggested that $\mathrm{PT}$ has the potential to attenuate oxidative stress and inflammation in asthma.

\section{ETHICS STATEMENT}

Animal care and experimental procedures were performed in accordance with the guidelines of the Laboratory Animal Care Committee of Chang Gung University of Science and Technology (IACUC approval number: 2014-023). Female BALB/c mice were obtained from the National Laboratory Animal Center in Taiwan. Mice were kept and maintained in air-conventional animal housing on a $12 \mathrm{~h}$ light/dark cycle. Before the experiment, the mice adapt the experimental environment of at least 1 week. The care and housing of experimental animals were approved in accordance with the guidelines of the Laboratory Animal Care Committee of Chang Gung University of Science.

\section{AUTHOR CONTRIBUTIONS}

Designed and performed the experiments: C-JL, L-WF, and $\mathrm{W}-\mathrm{CH}$; analysis and interpretation of data: L-WF and $\mathrm{W}-\mathrm{CH}$; drafting the manuscript: $\mathrm{C}-\mathrm{JL}$ and $\mathrm{W}-\mathrm{CH}$.

\section{FUNDING}

This study was supported, in part, by grants from the Ministry of Science and Technology in Taiwan (104-2320-B-255-001) and from Chang Gung University of Science and Technology (EZRPF3F0241 and EZRPF3F0251).

\section{REFERENCES}

1. Ray A, Raundhal M, Oriss TB, Ray P, Wenzel SE. Current concepts of severe asthma. J Clin Invest (2016) 126:2394-403. doi:10.1172/jci84144

2. Leinaar E, Alamian A, Wang L. A systematic review of the relationship between asthma, overweight, and the effects of physical activity in youth. Ann Epidemiol (2016) 26:504-510.e6. doi:10.1016/j.annepidem.2016.06.002

3. Wesolowska-Andersen A, Seibold MA. Airway molecular endotypes of asthma: dissecting the heterogeneity. Curr Opin Allergy Clin Immunol (2015) 15:163-8. doi:10.1097/aci.0000000000000148

4. Fahy JV. Type 2 inflammation in asthma - present in most, absent in many. Nat Rev Immunol (2015) 15:57-65. doi:10.1038/nri3786

5. KleinJan A. Airway inflammation in asthma: key players beyond the Th2 pathway. Curr Opin Pulm Med (2016) 22:46-52. doi:10.1097/ mcp.0000000000000224

6. Saglani S, Lloyd CM. Eosinophils in the pathogenesis of paediatric severe asthma. Curr Opin Allergy Clin Immunol (2014) 14:143-8. doi:10.1097/ aci. 0000000000000045

7. Nakagome K, Matsushita S, Nagata M. Neutrophilic inflammation in severe asthma. Int Arch Allergy Immunol (2012) 158(Suppl 1):96-102. doi:10.1159/000337801

8. Lin CC, Chu CL, Ng CS, Lin CY, Chen DY, Pan IH, et al. Immunomodulation of phloretin by impairing dendritic cell activation and function. Food Funct (2014) 5:997-1006. doi:10.1039/c3fo60548e

9. Huang WC, Dai YW, Peng HL, Kang CW, Kuo CY, Liou CJ. Phloretin ameliorates chemokines and ICAM-1 expression via blocking of the NF-kappaB

pathway in the TNF-alpha-induced HaCaT human keratinocytes. Int Immunopharmacol (2015) 27:32-7. doi:10.1016/j.intimp.2015.04.024

10. Huang WC, Chang WT, Wu SJ, Xu PY, Ting NC, Liou CJ. Phloretin and phlorizin promote lipolysis and inhibit inflammation in mouse 3T3-L1 cells and in macrophage-adipocyte co-cultures. Mol Nutr Food Res (2013) 57:1803-13. doi:10.1002/mnfr.201300001

11. Fordham JB, Naqvi AR, Nares S. Leukocyte production of inflammatory mediators is inhibited by the antioxidants phloretin, silymarin, hesperetin, and resveratrol. Mediators Inflamm (2014) 2014:938712. doi:10.1155/2014/ 938712

12. Huang WC, Lai CL, Liang YT, Hung HC, Liu HC, Liou CJ. Phloretin attenuates LPS-induced acute lung injury in mice via modulation of the NF-kappaB and MAPK pathways. Int Immunopharmacol (2016) 40:98-105. doi:10.1016/ j.intimp.2016.08.035

13. Huang WC, Liou CJ. Dietary acacetin reduces airway hyperresponsiveness and eosinophil infiltration by modulating eotaxin-1 and th 2 cytokines in a mouse model of asthma. Evid Based Complement Alternat Med (2012) 2012:910520. doi:10.1155/2012/910520

14. Huang WC, Chan CC, Wu SJ, Chen LC, Shen JJ, Kuo ML, et al. Matrine attenuates allergic airway inflammation and eosinophil infiltration by suppressing eotaxin and Th2 cytokine production in asthmatic mice. J Ethnopharmacol (2014) 151:470-7. doi:10.1016/j.jep.2013.10.065

15. Myou S, Leff AR, Myo S, Boetticher E, Tong J, Meliton AY, et al. Blockade of inflammation and airway hyperresponsiveness in immune-sensitized mice by dominant-negative phosphoinositide 3-kinase-TAT. J Exp Med (2003) 198:1573-82. doi:10.1084/jem.20030298 
16. Liou CJ, Lai YR, Chen YL, Chang YH, Li ZY, Huang WC. Matrine attenuates COX-2 and ICAM-1 expressions in human lung epithelial cells and prevents acute lung injury in LPS-induced mice. Mediators Inflamm (2016) 2016:3630485. doi:10.1155/2016/3630485

17. Paine A, Eiz-Vesper B, Blasczyk R, Immenschuh S. Signaling to heme oxygenase- 1 and its anti-inflammatory therapeutic potential. Biochem Pharmacol (2010) 80:1895-903. doi:10.1016/j.bcp.2010.07.014

18. Shu G, Lu NS, Zhu XT, Xu Y, Du MQ, Xie QP, et al. Phloretin promotes adipocyte differentiation in vitro and improves glucose homeostasis in vivo. JNutr Biochem (2014) 25:1296-308. doi:10.1016/j.jnutbio.2014. 07.007

19. Aldakheel FM, Thomas PS, Bourke JE, Matheson MC, Dharmage SC, Lowe AJ. Relationships between adult asthma and oxidative stress markers and $\mathrm{pH}$ in exhaled breath condensate: a systematic review. Allergy (2016) 71:741-57. doi:10.1111/all.12865

20. Antus B. Oxidative stress markers in sputum. Oxid Med Cell Longev (2016) 2016:2930434. doi:10.1155/2016/2930434

21. El-Sherbeeny NA, Hassan ZA, Ateyya H. Tiron ameliorates oxidative stress and inflammation in a murine model of airway remodeling. Int Immunopharmacol (2016) 39:172-80. doi:10.1016/j.intimp.2016.07.025

22. Fatani SH. Biomarkers of oxidative stress in acute and chronic bronchial asthma. J Asthma (2014) 51:578-84. doi:10.3109/02770903.2014.892965

23. Ma Y, Ge A, Zhu W, Liu YN, Ji NF, Zha WJ, et al. Morin attenuates ovalbumin-induced airway inflammation by modulating oxidative stressresponsive MAPK signaling. Oxid Med Cell Longev (2016) 2016:5843672. doi:10.1155/2016/5843672

24. Liu Y, Zhang L, Liang J. Activation of the Nrf2 defense pathway contributes to neuroprotective effects of phloretin on oxidative stress injury after cerebral ischemia/reperfusion in rats. J Neurol Sci (2015) 351:88-92. doi:10.1016/ j.jns.2015.02.045

25. Aliomrani M, Sepand MR, Mirzaei HR, Kazemi AR, Nekonam S, Sabzevari O. Effects of phloretin on oxidative and inflammatory reaction in rat model of cecal ligation and puncture induced sepsis. Daru (2016) 24:15. doi:10.1186/ s40199-016-0154-9

26. Tong X, Guo T, Liu S, Peng S, Yan Z, Yang X, et al. Macrolide antibiotics for treatment of asthma in adults: a meta-analysis of 18 randomized controlled clinical studies. Pulm Pharmacol Ther (2015) 31:99-108. doi:10.1016/ j.pupt.2014.09.005
27. Li YJ, Kawada T, Azuma A. Nrf2 is a protective factor against oxidative stresses induced by diesel exhaust particle in allergic asthma. Oxid Med Cell Longev (2013) 2013:323607. doi:10.1155/2013/323607

28. Steinke JW, Lawrence MG. T-cell biology in immunotherapy. Ann Allergy Asthma Immunol (2014) 112:195-9. doi:10.1016/j.anai.2013.12.020

29. Parulekar AD, Diamant Z, Hanania NA. Role of T2 inflammation biomarkers in severe asthma. Curr Opin Pulm Med (2016) 22:59-68. doi:10.1097/ mcp.0000000000000231

30. Hirahara K, Nakayama T. CD4+ T-cell subsets in inflammatory diseases: beyond the Th1/Th2 paradigm. Int Immunol (2016) 28:163-71. doi:10.1093/ intimm/dxw006

31. Girodet PO, Nguyen D, Mancini JD, Hundal M, Zhou X, Israel E, et al. Alternative macrophage activation is increased in asthma. Am J Respir Cell Mol Biol (2016) 55:467-75. doi:10.1165/rcmb.2015-0295OC

32. Hall S, Agrawal DK. Key mediators in the immunopathogenesis of allergic asthma. Int Immunopharmacol (2014) 23:316-29. doi:10.1016/ j.intimp.2014.05.034

33. Song MY, Wang J, Ka SO, Bae EJ, Park BH. Insulin secretion impairment in Sirt6 knockout pancreatic beta cells is mediated by suppression of the FoxO1-Pdx1-Glut2 pathway. Sci Rep (2016) 6:30321. doi:10.1038/srep30321

34. Rasmussen F, Hancox RJ. Mechanisms of obesity in asthma. Curr Opin Allergy Clin Immunol (2014) 14:35-43. doi:10.1097/ACI.0000000000000024

35. Kuhre RE, Bechmann LE, Wewer Albrechtsen NJ, Hartmann B, Holst JJ. Glucose stimulates neurotensin secretion from the rat small intestine by mechanisms involving SGLT1 and GLUT2, leading to cell depolarization and calcium influx. Am J Physiol Endocrinol Metab (2015) 308:E1123-30. doi:10.1152/ajpendo.00012.2015

Conflict of Interest Statement: The authors declare that the research was conducted in the absence of any commercial or financial relationships that could be construed as a potential conflict of interest.

Copyright (c) 2017 Huang, Fang and Liou. This is an open-access article distributed under the terms of the Creative Commons Attribution License (CC BY). The use, distribution or reproduction in other forums is permitted, provided the original author(s) or licensor are credited and that the original publication in this journal is cited, in accordance with accepted academic practice. No use, distribution or reproduction is permitted which does not comply with these terms. 